\title{
Venäläinen urheiluelokuva vuonna 2018
}

Urheiluelokuva on genre, jota harvoin erikseen nostetaan esille. Venäjällä on kuitenkin 2000-luvun aikana ilmestynyt muutamakin urheiluelokuva vuodessa, esimerkkeinä historiallista jääkiekko-ottelua kuvannut Legenda n:o 17 (2013) tai nuorten monikulttuurisen jalkapallojoukkueen taivalta kartoittanut Korobka (2016). Mutta täysin ilmiömäisenä elokuvahistoriaan nousee vuosi 2018, jolloin kolme vuoden katsotuinta kotimaista elokuvaa sijoittuivat kaikki tavalla tai toisella urheilun maailmaan.

Nämä uudet urheiluelokuvat ovat rikkoneet kaikkien aikojen ennätykset kotimaisten elokuvien lipputuotoissa ja katsojamäärissä. Paradoksaalisesti samalla elokuvabisneksen kokonaismarkkinat ovat taantuneet; käytännössä siis ulkomaisen - eli pääosin amerikkalaisen - elokuvan kysyntä on kutistunut. Venäjän kulttuuriministeriön viime vuosien erityispanostus kotimaisen elokuvateollisuuden kehittämiseen on vihdoin alkanut tuottaa tulosta.

Koripalloelokuva Dviženije vverh (2017) sai ensi-iltansa loppuvuodesta 2017 ja nousi vuoden 2018 aikana Venäjän kaikkien aikojen katsotuimmaksi elokuvaksi. Elokuva käsittelee vuoden 1972 Münchenin olympialaisissa tunteita kuohuttanutta kultaottelua Neuvostoliiton ja USA:n välillä. Media on näyttävästi osallistunut elokuvan hypeen, esim. nettisivusto gazeta. ru uutisoi (24.10.2018) näyttävästi tapauksesta, jossa jekaterinburgilainen koululainen oli saanut liikunnasta huonon arvosanan jätettyään elokuvan katsomatta - onneksi kyseessä oli väärinkäsitys, joka sittemmin korjattiin. 
Ljod (2018) on puolestaan komedia ja musiikkielokuva, joka kuvaa taitoluistelijan ja jääkiekkoilijan herkän romanttista kohtaamista sekä yhteistä taistelua unelmien saavuttamiseksi. Romanttinen komedia onkin tasaisen vahvasti ollut yksi Neuvostoliiton jälkeisen venäläisen elokuvan suosituimpia genrejä. Luisteluelokuvan ensi-ilta oli ystävänpäivänä ja mainoslauseena toiveikas "Vesna blizko" ["Kevät on lähellä"]. Kuvauspaikkoina toimivat Moskovan ohella myös talvinen Baikal-järvi sekä Sotšin olympialaisissa käytetyt luisteluareenat.

Kun top-10 listasta siivotaan pois amerikkalaiset elokuvat, niin kolmanneksi vuoden 2018 katsotuimpien elokuvien kärkeen kiilaa jalkapalloelokuva Trener (2018). Kolmekymppisen näyttelijätähti Danila Kozlovskin esikoisohjaus kertoo huippujalkapalloilijasta, joka epäonnistumisen jälkeen siirtyy syrjään ja alkaa valmentaa pientä, tuntematonta joukkuetta kohtaamaan elämän suuret voitot ja tappiot. Elokuva sai ensi-iltansa juuri ennen 2018 FIFA World Cup -kilpailuja, joiden isäntämaana Venäjä toimi - ensimmäisenä Itä-Euroopan maana kautta aikojen.

Teksti: Ira Österberg Kuvat: Central Partnership ja Art Pictures Group. 


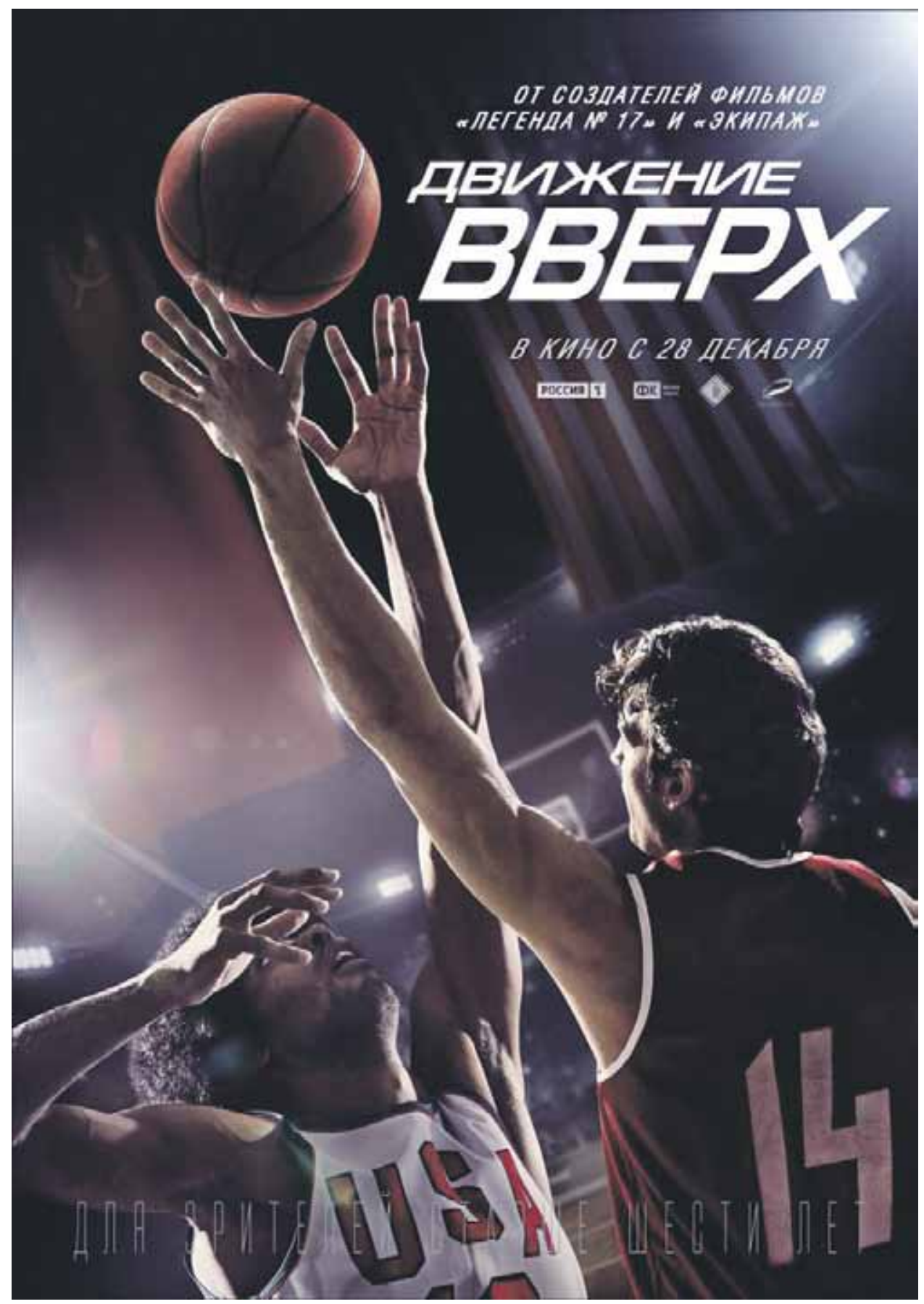



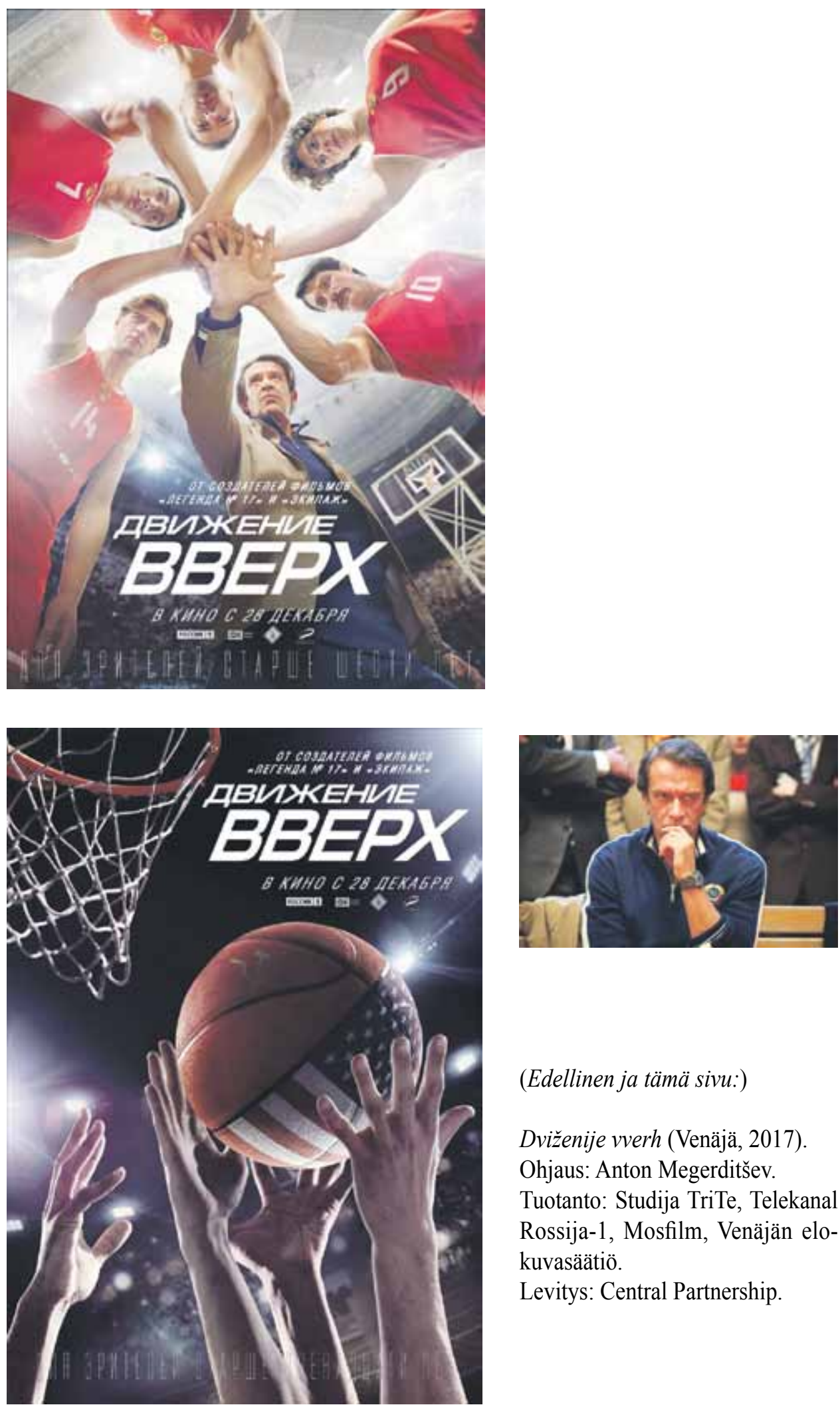

(Edellinen ja tämä sivu:)

Dviženije vverh (Venäjä, 2017).

Ohjaus: Anton Megerditšev.

Tuotanto: Studija TriTe, Telekanal Rossija-1, Mosfilm, Venäjän elokuvasäätiö.

Levitys: Central Partnership. 

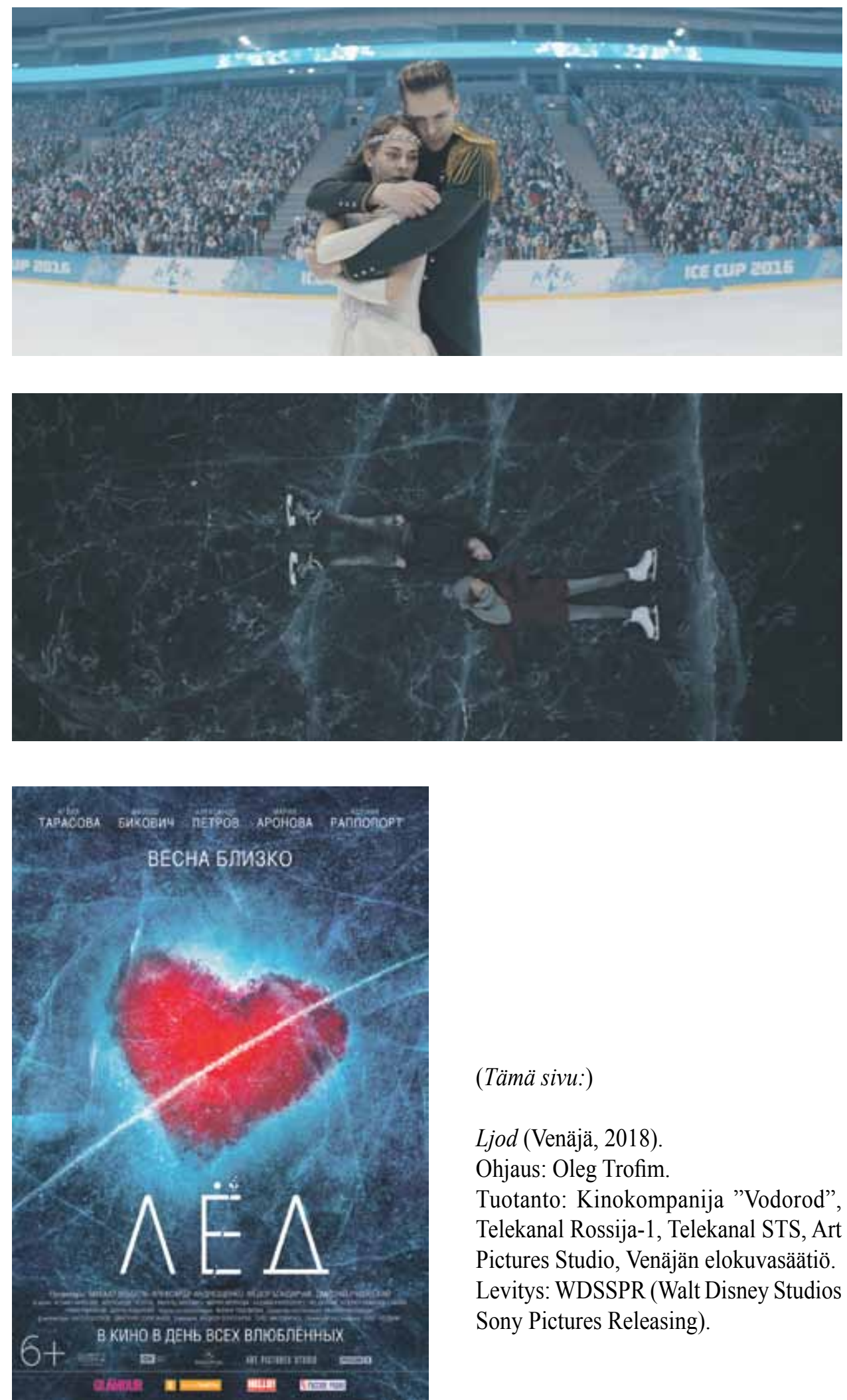

(Tämä sivu:)

Ljod (Venäjä, 2018).

Ohjaus: Oleg Trofim.

Tuotanto: Kinokompanija "Vodorod", Telekanal Rossija-1, Telekanal STS, Art Pictures Studio, Venäjän elokuvasäätiö. Levitys: WDSSPR (Walt Disney Studios Sony Pictures Releasing). 

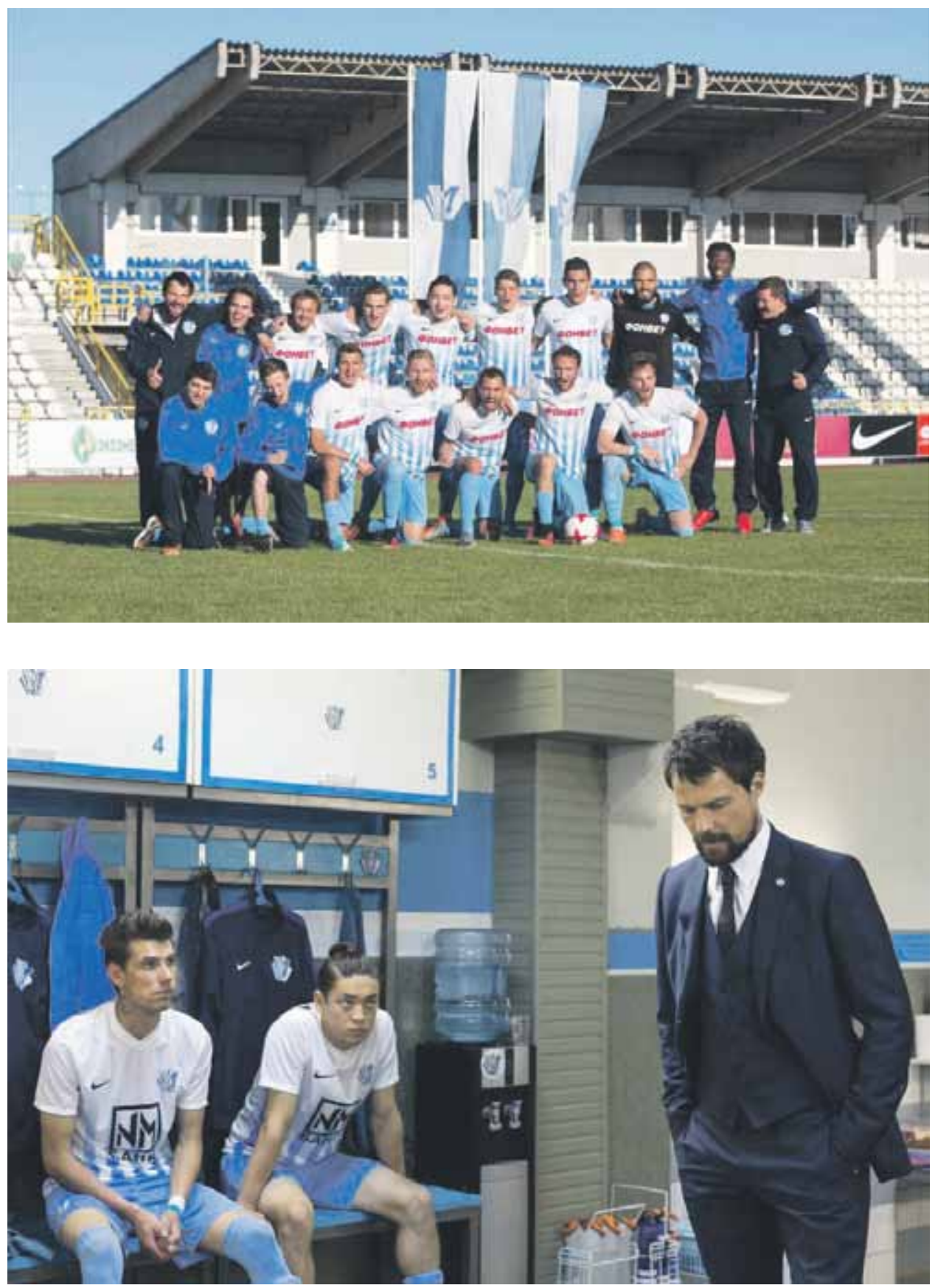

(Tämä ja seuraava sivu:)

Trener (Venäjä, 2018).

Ohjaus: Danila Kozlovski. Tuotanto: Kinoslovo, Studija TriTe, DK Entertainment, Telekanal Rossija-1, Mosfilm, Venäjän elokuvasäätiö.

Levitys:.Central Partnership. 


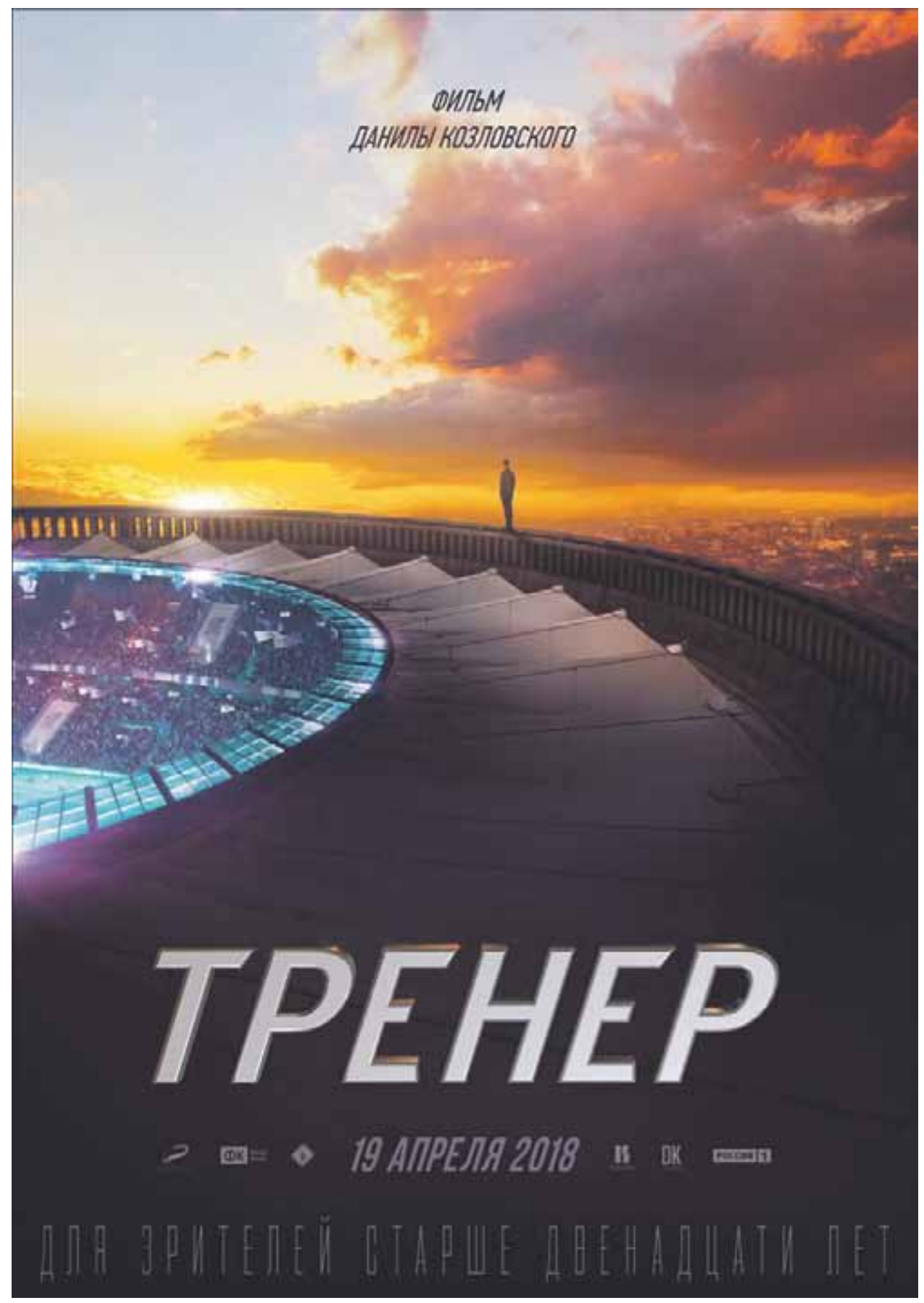

